\title{
ON NON-ELLIPTIC REGIONS AND SOLVABILITY OF BALANCE EQUATIONS FOR ATMOSPHERE DYNAMICS
}

\author{
ANDREI BOURCHTEIN \& LUDMILA BOURCHTEIN
}

\author{
Institute of Physics and Mathematics, Pelotas State University, Brazil \\ Correspondence address: Rua Anchieta 4715 bloco K, ap.304, Pelotas-RS 96015-420, Brazil \\ E-mail: burstein@terra.com.br
}

Received April 2006 - Accepted July 2006

\begin{abstract}
To eliminate the fast gravitational waves of great amplitude, which are not observed in the real atmosphere, the initial fields for numerical schemes of atmosphere forecasting and modeling systems are usually adjusted dynamically by applying balance relations. In this study we consider different forms of the balance equations and for each of them we detect the nonelliptic regions in the gridded atmosphere data of the Southern Hemisphere. The performed analysis reveals the geographical, vertical and zonally averaged distributions of nonelliptic regions with the most concentration in the tropical zone. The area of these regions is essentially smaller and less intensive for more complete and physically justified balance relations. The obtained results confirm the Kasahara's assumption that ellipticity conditions are violated in the actual atmospheric fields essentially due to approximations made under deriving the balance equations.
\end{abstract}

Keywords: balance equations, initialization methods, nonelliptic regions

\section{RESUMO: SOBRE REGIÕES NÃO ELÍPTICAS E SOLVABILIDADE DE EQUAÇÕES DE BALANÇO PARA DINÂMICA DA ATMOSFERA.}

Para eliminar as ondas gravitacionais rápidas de grande amplitude, as quais não se observam na atmosfera real, os campos iniciais para esquemas numéricos de sistemas de modelagem e previsão atmosférica são usualmente ajustados dinamicamente aplicando as relações de balanço. Neste estudo consideramos formas diferentes de equações de balanço e para cada uma dessas detectamos as regiões não elípticas nos dados atmosféricos do Hemisfério Sul. A analise realizada mostra a distribuição geográfica, vertical e média zonal de regiões não elípticas com maior concentração na zona tropical. A área dessas regiões é essencialmente reduzida e a intensidade é visivelmente menor para as relações de balanço mais completas e fisicamente justificáveis. Os resultados obtidos confirmam a suposição de Kasahara de que as condições de ellipticidade são violadas nos campos atmosféricos reais essensialmente devido às aproximações feitas em dedução das equações de balanço.

Palavras-chave: equações de balanço, métodos de inicialização, regiões não elípticas

\section{INTRODUCTION}

Numerical weather prediction, which is the core activity of atmospheric research and operational centers, consists basically of computation of solution to a set of partial differential equations expressing the conservation laws of mass, momentum and energy for compressible continuum medium in the non-inertial system related to a rotating sphere. The chosen differential model is solved numerically as initial value (or initial-boundary value) problem, requiring the definition of initial data. Data assimilation schemes supply these initial conditions, but they may not be well dynamically adjusted, which means that fast oscillations of great amplitude, which are not observed in the real atmosphere, are generated at the initial stages of the numerical solution. These oscillations may contaminate physically meaning solution up to some days of forecast depending on the mechanisms of physical and computational diffusion included in the model. The process of adjusting the initial data to the prediction model to ensure small amplitudes of the fast waves is called initialization. 
The long history of balance relations aimed to adjust the initial data may be traced back to the famous nonlinear balance equation by Charney (1955). A review of various initialization procedures, including nonlinear balance and omega equations, developed up to mid 70's, is given by Bengtsson (1975). The current approaches to initial adjustment include nonlinear normal mode initialization (NMI) introduced by Machenhauer (1977) and Baer and Tribbia (1977), boundary derivative method (BDM) presented first by Browning et al. (1980) and digital filter technique proposed by Lynch et al. (e.g., Lynch and Huang 1992). One of the most effective versions of the NMI is the vertical (or implicit) normal mode initialization (Bourke and McGregor 1983, Temperton 1988, Fillion and Roch 1992), which is equivalent to BDM approach (Kasahara 1982, Bijlsma and Hafkenscheid 1986, McGregor and Bourke 1988).

In his seminal paper, Daley (1981) presented the basic concepts of initialization and formulated a series of problems whose solution may improve understanding the principal properties of initialization equations. In this study we investigate one of these issues: the non-ellipticity of the balance diagnostic relations under fixed pressure field, so-called pressure (geopotential) constrained initialization. In the last years the initialization procedure was dropped in some atmospheric centers due to increased quality of observational network and objective analysis. Even having this tendency, the solution of the stated problem is important on its own because it could clarify a nature of the balance involving atmospheric fields.

The first studies of the ellipticity conditions for balance relations were made by Charney (1955) and Houghton (1968) in the case of nonlinear balance equation on the f-plane and on the sphere. Since the last equation is the particular case of the Monge-Amper equation (Charney 1955, Kasahara 1982), these studies essentially were the applications of the well-developed theory of Monge-Ampere equation.

The first theoretical study on the non-ellipticity of simplified NMI/BDM equations was presented by Tribbia (1981), who constructed theoretical example demonstrating that a certain restriction on meteorological fields must be satisfied in order to obtain a solution of the initialization system with fixed geopotential. He used the model of isolated barotropic vorticity on the f-plane and obtained that this restriction is close to ellipticity condition of the nonlinear balance equation. The violation of ellipticity condition can lead to the divergence of the iterative method of solving the NMI/BDM equations when the height constrained initialization is required. This problem was first reported by Daley (1978) when applying Machenhauer iteration procedure to the shallow water equations. The speculations about the reasons for this problem centered on two possibilities: the shortcomings of applied iterative algorithms and the mathematical inconsistency of the boundary value problem due to existence of nonelliptic regions in the real atmospheric data (Daley 1981, Tribbia 1981, Errico 1983, Rasch 1985).

Among different studies on nonelliptic regions in the isobaric height fields we should note the papers by Kasahara (1982), Paegle et al. (1983) and Knox (1997), and discussion of the respective issues by Daley (1991). As it was pointed out by Kasahara (1982), in the past the occurrence of these regions used to be considered as a result of observational inaccuracies even though the changes made to recover ellipticity criterion sometimes exceeded probable data errors, specially at higher levels. Probably, Kasahara (1982) was the first who stated in an explicit way that the ellipticity condition is a mathematical constraint on atmospheric fields, which can produce nonelliptic regions, and, consequently, impossibility of the required balance, simply because the assumptions made in deriving the balance relations could be not totally satisfied in real atmosphere. Therefore, one of the points of the different studies (e.g., Kasahara 1982, Paegle et al. 1983, Randel 1987 and Knox 1997) is to "adjust" ellipticity conditions by including the terms neglected in nonlinear balance relations. The new conditions, called realizability conditions, have essentially reduced the area of nonelliptic regions supporting the Kasahara's supposition. However this approach is based on evaluation of the contribution of different terms of the primitive divergence equation for possibly recovering the ellipticity of regions rather than on the consistent system of balance relations. The only considered balance equation was the nonlinear balance equation on the f-plane or on the sphere.

In the recent years some new and more complex mathematical criterions of ellipticity have been obtained for NMI/BDM equations, which are much more general balance system based on more accurate and reliable assumptions than nonlinear balance equation (Bourchtein 2002, Bourchtein 2006). In this way, many terms neglected in the derivation of the nonlinear balance equation have been recovered in NMI/BDM equations. Therefore, one can expect that respective ellipticity conditions should be more soft and related nonelliptic regions should be more scarce in order to confirm the Kasahara's statement.

In the present study we compare nonelliptic regions related to nonlinear balance equation (on the f-plane and sphere) and NMI/BDM equations for the shallow water model. In section 2 we present the NMI/BDM equations for the shallow water model and give a brief exposition of the respective ellipticity conditions. The results of the evaluation of nonelliptic regions in South Hemisphere for different balance relations are presented in section 3 followed by concluding remarks in section 4 . 


\section{BALANCE EQUATIONS AND ELLIPTICITY CONDITIONS}

In local Cartesian coordinates $\mathrm{x}, \mathrm{y}$ the classic nonlinear balance equation on a tangent plane has the form (Charney 1955)

$\overline{\mathrm{f}} \nabla^{2} \psi+2\left(\psi_{\mathrm{xx}} \psi_{\mathrm{yy}}-\psi_{\mathrm{xy}}{ }^{2}\right)-\nabla^{2} \Phi=0$,

where $\psi$ is the streamfunction, $\Phi$ is the geopotential, $\overline{\mathrm{f}}$ is a chosen value of the Coriolis parameter $\mathrm{f}$, and $\nabla^{2}$ is the Laplace operator. Considered as equation for the streamfunction with a given geopotential field, it is a special case of Monge-Ampere equation. If this equation is to be solved on bounded domain $\mathrm{D}$ with imposed values of the streamfucntion on the boundary $\partial \mathrm{D}$, then the problem is well posed only if the equation is of elliptic type. It requires the ellipticity condition to be satisfied, which has the following form for equation (1):

$\mathrm{E}_{1}=\nabla^{2} \Phi+\frac{\overline{\mathrm{f}}^{2}}{2}>0$.

Similarly, using spherical coordinates $\lambda$ (longitude) and $\varphi$ (latitude), the nonlinear balance equation assumes the form (Houghton 1968)

$$
\begin{aligned}
& \mathrm{f} \nabla^{2} \psi+2 \frac{1}{\mathrm{a}^{2} \cos \varphi}\left(\mathrm{u}_{\lambda} \mathrm{v}_{\varphi}-\mathrm{u}_{\varphi} \mathrm{v}_{\lambda}\right)-\beta \mathrm{u} \\
& -\frac{1}{\mathrm{a} \cos \varphi}\left(\sin \varphi \frac{\mathrm{u}^{2}+\mathrm{v}^{2}}{\mathrm{a}}\right)_{\varphi}-\nabla^{2} \Phi=0,
\end{aligned}
$$

where a is the Earth's radius, $\mathrm{f}=2 \Omega \sin \varphi, \mathrm{b}=2 \Omega \cos \varphi / \mathrm{a}, \Omega$ is the angular velocity of the Earth's rotation and $u$ and $v$ are the longitudinal and meridional components, respectively, of nondivergent wind, that is,

$\mathrm{u}=-\frac{\psi_{\varphi}}{\mathrm{a}}, \mathrm{v}=\frac{\psi_{\lambda}}{\mathrm{a} \cos \varphi}$.

Again, the solution of the boundary value problem for (3) with respect to the streamfunction requires the ellipticity condition, which can be written as follows (Houghton 1968):

$$
\mathrm{E}_{2}=\nabla^{2} \Phi+\frac{\mathrm{f}^{2}}{2}+\beta \mathrm{u}+\frac{\mathrm{u}^{2}+\mathrm{v}^{2}}{\mathrm{a}^{2}}>0 .
$$

The NMI/BDM systems have much more complex structure and contain a set of equations. For the shallow water equations on a sphere, the system contains two equations, which can be expressed in longitude-latitude coordinates $(\lambda, \varphi)$ as follows (Browning et al. 1980, Bourke and McGregor 1983, Temperton 1988):

$$
\begin{aligned}
& \nabla^{2} \Phi-\overline{\mathrm{f}} \operatorname{curl}_{2}(\mathrm{u}, \mathrm{v})=\operatorname{div}_{2}\left(\mathrm{Q}_{\mathrm{u}}, \mathrm{Q}_{\mathrm{v}}\right), \\
& \left(\bar{\Phi} \nabla^{2}-\overline{\mathrm{f}}^{2}\right)\left(\operatorname{div}_{2}(\mathrm{u}, \mathrm{v})\right)=\nabla^{2} \mathrm{Q}_{\Phi}-\overline{\mathrm{f}} \operatorname{curl}_{2}\left(\mathrm{Q}_{\mathrm{u}}, \mathrm{Q}_{\mathrm{v}}\right),
\end{aligned}
$$

where

$$
\begin{aligned}
& \operatorname{div}_{2}(\mathrm{U}, \mathrm{V})=\frac{1}{\mathrm{a} \cos \varphi}\left[\mathrm{U}_{\lambda}+(\cos \varphi \mathrm{V})_{\varphi}\right], \\
& \operatorname{curl}_{2}(\mathrm{U}, \mathrm{V})=\frac{1}{\mathrm{a} \cos \varphi}\left[\mathrm{V}_{\lambda}-(\cos \varphi \mathrm{U})_{\varphi}\right], \\
& \nabla^{2} \mathrm{~h}=\frac{1}{\mathrm{a} \cos \varphi}\left[\frac{1}{\cos \varphi} \mathrm{h}_{\lambda \lambda}+\left(\cos \varphi \mathrm{h}_{\varphi}\right)_{\varphi}\right]
\end{aligned}
$$

for any vector function $(\mathrm{U}, \mathrm{V})$ and any scalar function h. Here $\mathrm{u}$ and $\mathrm{v}$ are the (full) physical components of velocity, $\bar{\Phi}$ is a mean geopotential height and $\mathrm{Q}_{u}, \mathrm{Q}_{v}, \mathrm{Q}_{\Phi}$ contain all the nonlinear and variable coefficient terms of the shallow water equations, that is,

$$
\begin{aligned}
& \mathrm{Q}_{\mathrm{u}}=-\frac{\mathrm{u}}{\mathrm{a} \cos \varphi} \mathrm{u}_{\lambda}-\frac{\mathrm{v}}{\mathrm{a}} \mathrm{u}_{\varphi}+\frac{1}{\mathrm{a}} \tan \varphi \mathrm{uv}+(\mathrm{f}-\overline{\mathrm{f}}) \mathrm{v}, \\
& \mathrm{Q}_{\mathrm{v}}=-\frac{\mathrm{u}}{\mathrm{a} \cos \varphi} \mathrm{v}_{\lambda}-\frac{\mathrm{v}}{\mathrm{a}} \mathrm{v}_{\varphi}+\frac{1}{\mathrm{a}} \tan \varphi \mathrm{u}^{2}-(\mathrm{f}-\overline{\mathrm{f}}) \mathrm{u}, \\
& \mathrm{Q}_{\Phi}=-\frac{\mathrm{u}}{\mathrm{a} \cos \varphi} \Phi_{\lambda}-\frac{\mathrm{v}}{\mathrm{a}} \Phi_{\varphi}-(\Phi-\bar{\Phi}) \operatorname{div}_{2}(\mathrm{u}, \mathrm{v}) .
\end{aligned}
$$

The system (6)-(7) contains three unknown functions $\mathrm{u}$, $\mathrm{v}$ and $\Phi$, so it admits different closure conditions. The following natural versions of these conditions are frequently considered (Daley 1981, Daley 1991):

$$
\begin{aligned}
& \mathrm{p} \equiv \bar{\Phi} \nabla^{2} \psi-\overline{\mathrm{f}} \Phi=\mathrm{p}_{0}, \\
& \psi=\psi_{0}, \\
& \text { or } \\
& \Phi=\Phi_{0},
\end{aligned}
$$

i.e., initialization with unchanged slow mode p (frequently called unconstrained initialization), unchanged streamfunction $\psi$ (streamfunction constrained initialization) or unchanged geopotential $\Phi$ (geopotential constrained initialization). Function $p$ is the potential vorticity of the linearized barotropic equations on the f-plane. The nonlinear system of partial differential equations (6)-(7) with one of the closure conditions (10), (11) or (12) forms well-posed boundary value problem if it is elliptic. The ellipticity is guaranteed if its homogeneous form (characteristic determinant) is definite, that is, it does not change sign in the domain $\mathrm{D}$ of the problem.

For each of the closure conditions (10)-(12) the ellipticity criterion of the respective differential problem have been derived in Bourchtein (2002) and Bourchtein (2006). In particular, it was shown that the closures (10) and (11) generate the same ellipticity condition in the simple form

$\bar{\Phi}>\mathrm{u}^{2}+\mathrm{v}^{2}$.

It means that the boundary value problem for NMI/BDM with unchanged streamfunction can be well posed if, and only if, the phase speed of gravitational waves $c=\sqrt{\bar{\Phi}}$ is greater than 
the advective speed throughout the entire domain D. Of course, this condition is satisfied for the barotropic model equations of the atmosphere and for the first (fastest) vertical modes of a baroclinic model. However, the condition (13) is violated for very thin layers, which is the cause of the divergence of iterative algorithms applied to solve the initialization equations. Respectively, a similar behavior can be expected for slow internal modes of a baroclinic model and was observed in numerical experiments with different multilevel models reported in many papers (e.g., Daley 1981, Errico 1983, Temperton and Roch 1991).

If the geopotential constrained initialization is used, the ellipticity condition is much more complex and its approximate form in spherical coordinates can be written as follows (Bourchtein 2006):

$$
\begin{aligned}
& \mathrm{E}_{3}=\left(\mathrm{f} \frac{1}{\cos \varphi}-2 \mathrm{u}_{\varphi} \frac{1}{\mathrm{a} \cos \varphi}\right)\left(\mathrm{f} \cos \varphi+2 \mathrm{v}_{\lambda} \frac{1}{\mathrm{a}}\right) \\
& -\left(\mathrm{u}_{\lambda} \frac{1}{\mathrm{a} \cos \varphi}-\mathrm{v}_{\varphi} \frac{1}{\mathrm{a}}\right)^{2}>0 .
\end{aligned}
$$

In the next section we show that this condition can be violated in some points of the analysis data. Even though the area covered by points with the negative values of $\mathrm{E}_{3}$ is usually small in comparison with the total area of a chosen domain, it leads to mathematical inconsistency of the boundary value problem for considered differential equations. This inconsistency causes divergence of any iterative method applied to solve the boundary value problem. In this way, we confirm the Daley assumption that the reason behind the problem of divergence is of mathematical nature.

\section{ANALYSIS OF DISTRIBUTION OF THE NONELLIPTIC REGIONS}

In this section we apply the ellipticity criteria (2), (5) and (14) to investigate the occurrence of the respective nonelliptic regions in the gridded data of the NCEP (National Centers for Environmental Prediction) analysis for the Southern Hemisphere. The data for this study were taken from the global NCEP analysis available on a spatial grid with regular latitude/ longitude resolution of $1^{0}$ and 26 vertical pressure levels. The analysis was restricted to the data of the Southern Hemisphere at 850,500 and $200 \mathrm{hPa}$ pressure levels for 0000 GMT 05 November 2005. The meteorological elements used are the longitudinal and meridional velocity components $\mathrm{u}$ and $\mathrm{v}$, and the geopotential $\Phi$.

First, we compute the ellipticity measures $E_{1}$ and $E_{2}$ defined by (2) and (5) on three chosen pressure levels. The nondivergent velocity components in (5) were evaluated by formula (4) with the streamfunction found from Poisson's equation $\nabla^{2} \psi=\zeta$, where the Laplace operator is defined in (9) and $\zeta$ is the relative vorticity defined by the second formula in (8) with gridded data of the velocity components $u$ and $v$. The obtained values of $E_{2}$ are systematically slightly greater than $\mathrm{E}_{1}$, but the difference is too small and can be certainly neglected for this study. The charts of the distribution of $E_{2}$ are shown on Figs.1-6 separately for each pressure surface and Eastern and Western Hemispheres. Contour intervals are $4 \cdot 10^{-8} \mathrm{~s}^{-2}$. To avoid the "noisy" maps, only nonelliptic regions are plotted. It can be seen the strong tendency in increasing the nonelliptic area toward higher levels. There is some relation between nonelliptic area location at different levels but it is not observed systematically. At each pressure surface the nonelliptic regions mostly appear in the tropics and subtropics, though there are some nonelliptic regions in the middle and even high latitudes as well. The geographical distribution of the nonelliptic regions in the tropics appears to be almost random. To give one example of the relation between measures $\mathrm{E}_{1}$ and $\mathrm{E}_{2}$ we also show the chart of $\mathrm{E}_{1}$ for 500 pressure surface, Western Hemisphere (Fig.7). As one can see the values of two measures are virtually identical for the purpose of our study. Therefore, hereafter we use only the measure $\mathrm{E}_{2}$, which is theoretically more complete.

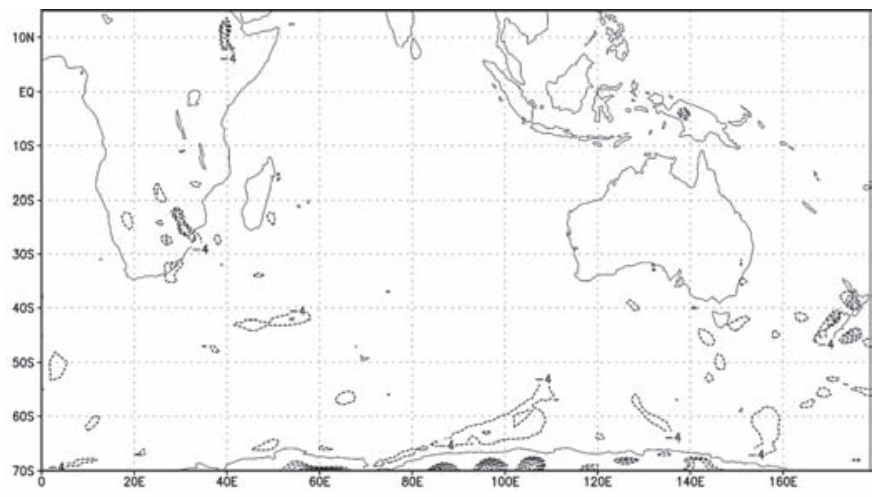

Figure 1 - Distribution of the nonelliptic regions according to measure $\mathrm{E}_{2}$ in the East part of the Southern Hemisphere at $850 \mathrm{hPa}$ pressure level.

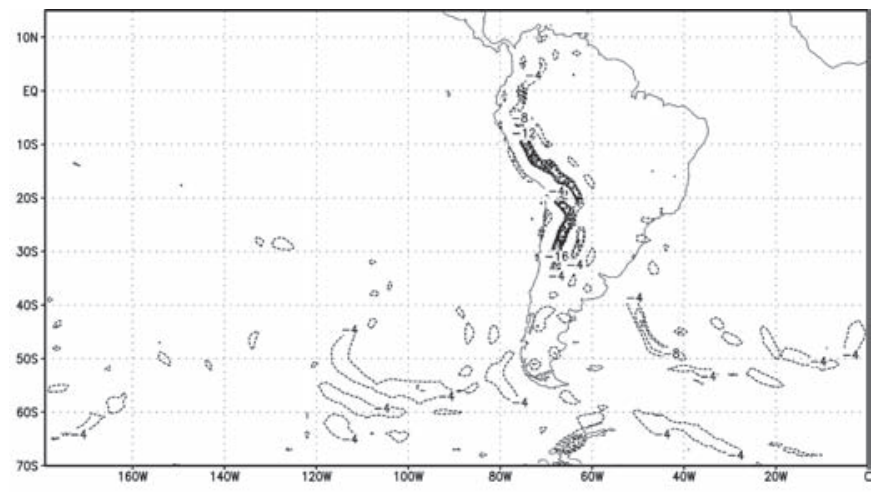

Figure 2 - Same as in Figure 1, except for the West part of the Southern Hemisphere. 


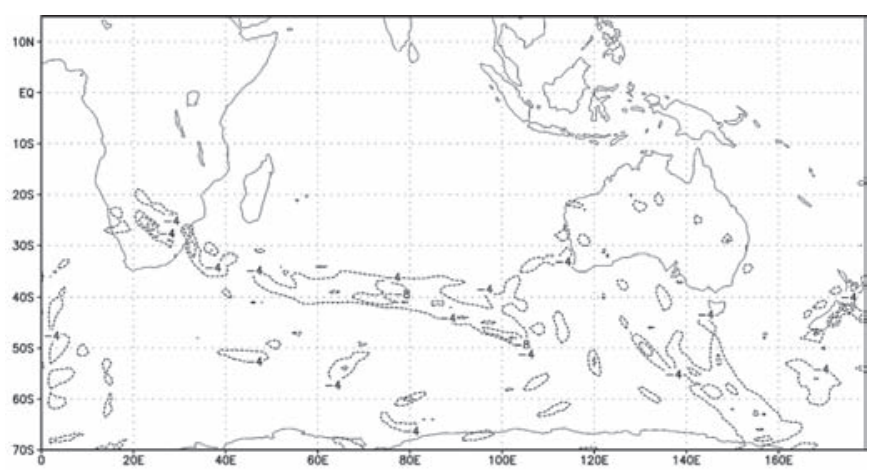

Figure 3 - Same as in Figure 1, except for the $500 \mathrm{hPa}$ pressure level.

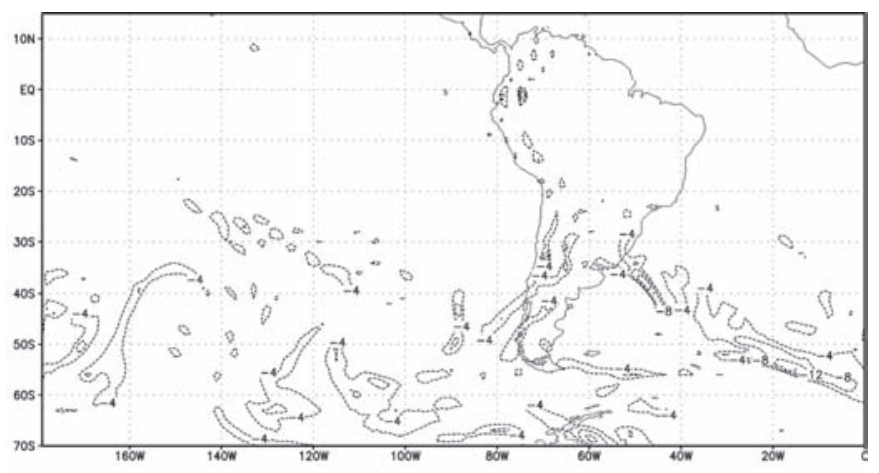

Figure 4 - Same as in Figure 2, except for the $500 \mathrm{hPa}$ pressure level.

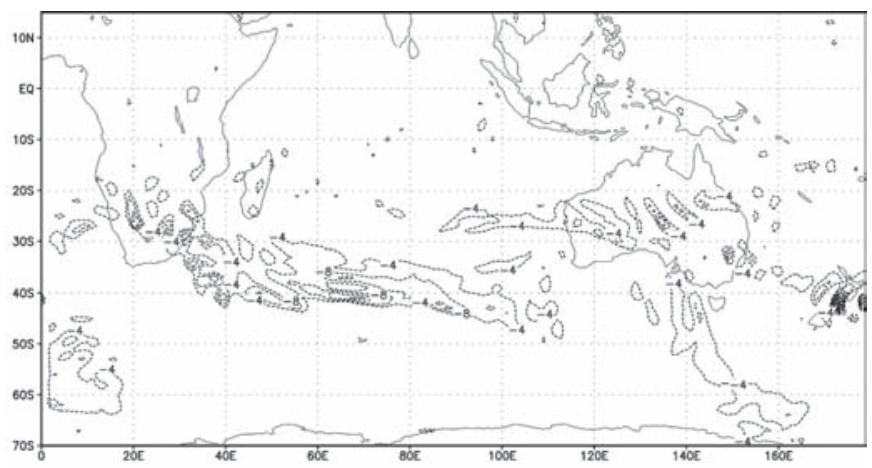

Figure 5 - Same as in Figure 1, except for the $200 \mathrm{hPa}$ pressure level.

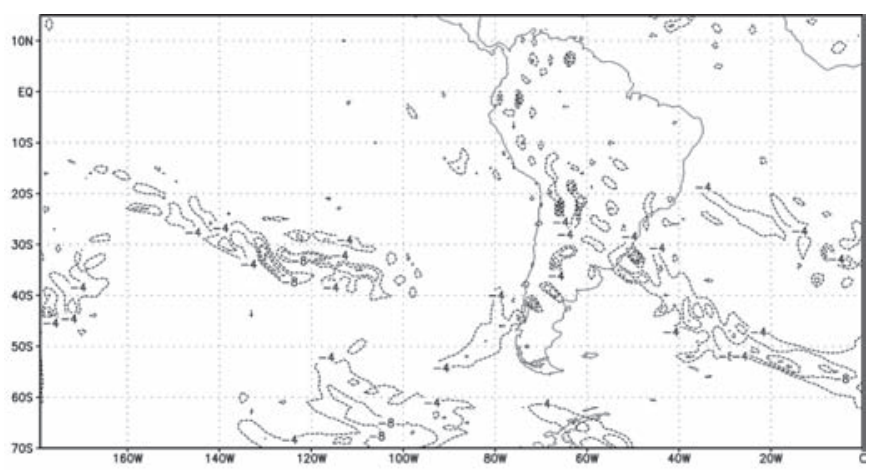

Figure 6 - Same as in Figure 2, except for the $200 \mathrm{hPa}$ pressure level.

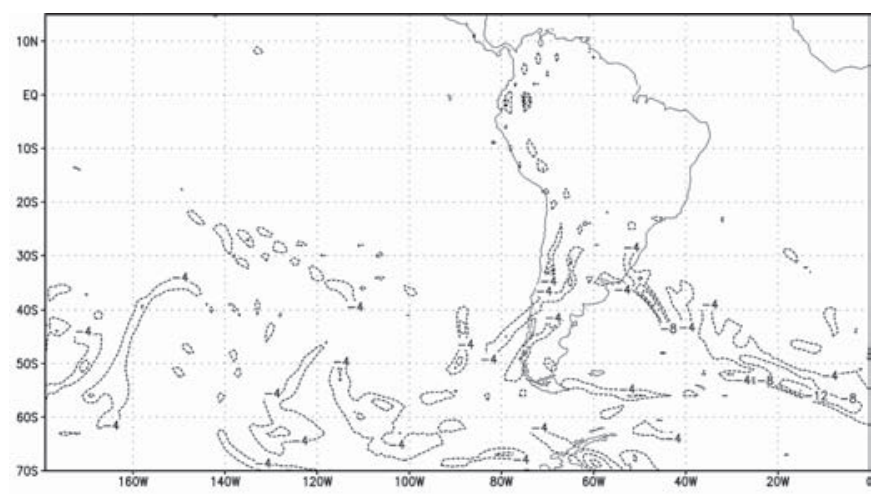

Figure 7 - Same as in Figure 4, except for the measure $E_{1}$.

The following series of six charts (Figs.8-13) shows the elliptic measure $\mathrm{E}_{3}$ for corresponding surfaces and Hemispheres. Contour intervals are $2 \cdot 10^{-9} \mathrm{~s}^{-2}$ and again only the nonelliptic regions are plotted. On all charts for $\mathrm{E}_{3}$ the nonelliptic regions cover significantly less area and have much less intensity in comparison with the measure $\mathrm{E}_{2}$. The spatial distribution of the nonelliptic $\mathrm{E}_{3}$ areas seems to follow the pattern of the measure $\mathrm{E}_{2}$ : these are more concentrated in tropic and subtropic zone with rather chaotic geographical distribution and increased area and intensity at the $200 \mathrm{hPa}$ pressure level.

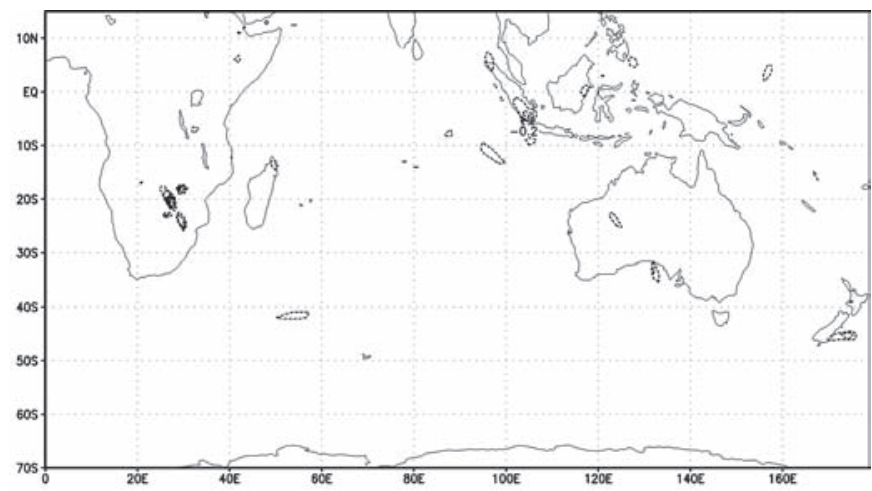

Figure 8-Distribution of the nonelliptic regions according to measure $\mathrm{E}_{3}$ in the East part of the Southern Hemisphere at $850 \mathrm{hPa}$ pressure level.

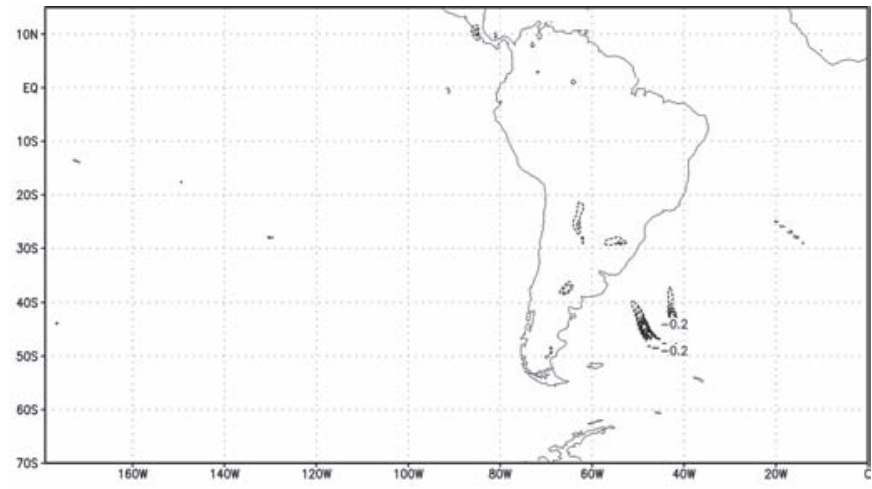

Figure 9-Same as in Figure 8, except for the West part of the Southern Hemisphere. 


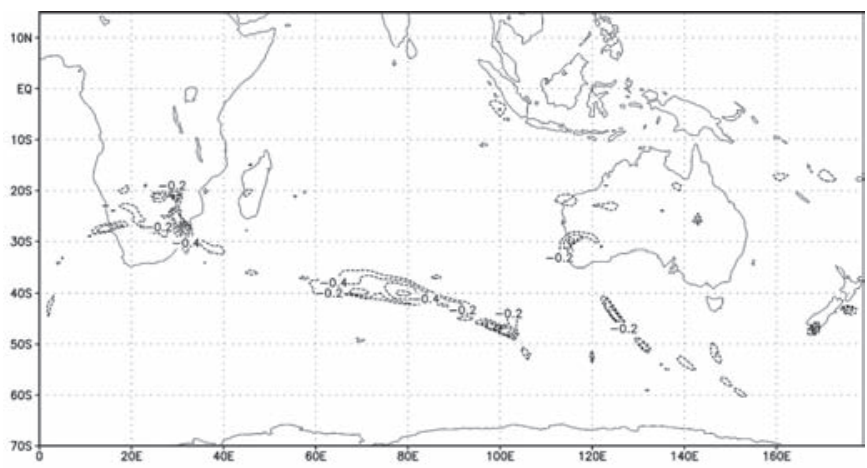

Figure 10 - Same as in Figure 8, except for the $500 \mathrm{hPa}$ pressure level.

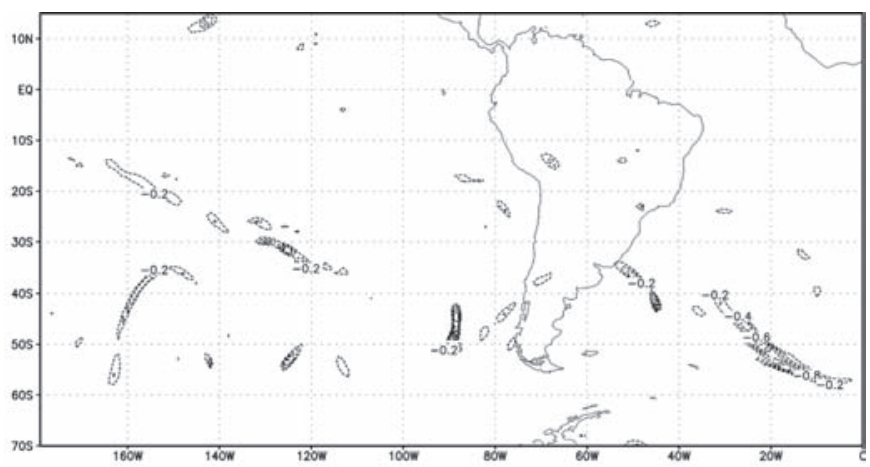

Figure 11 - Same as in Figure 9, except for the $500 \mathrm{hPa}$ pressure level.

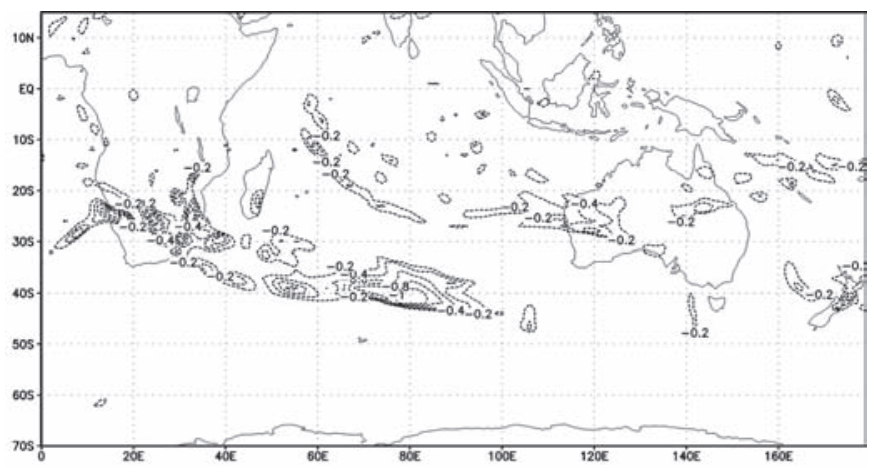

Figure 12 - Same as in Figure 8, except for the $200 \mathrm{hPa}$ pressure level.

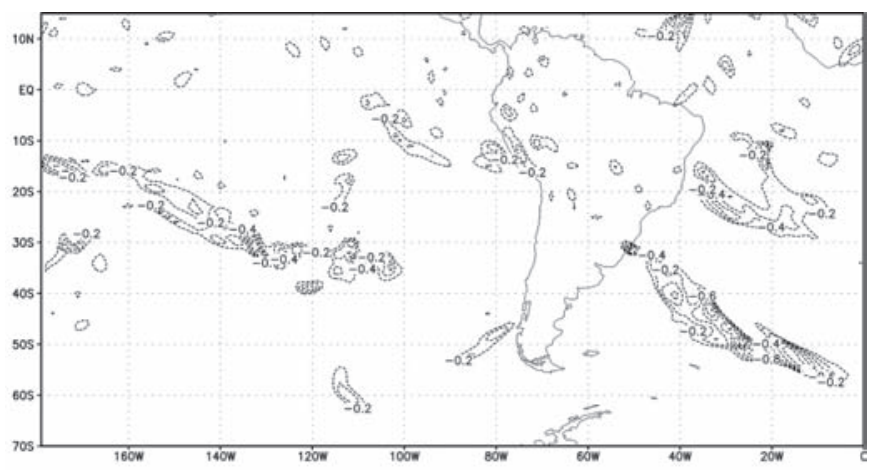

Figure 13 - Same as in Figure 9, except for the $200 \mathrm{hPa}$ pressure level.
As it was pointed out by different researchers (e.g., Kasahara 1982, Knox 1997), an area average of ellipticity measure is another important index for examining the nature of nonelliptic regions. The longitudinal averages of the measures $E_{2}$ and $E_{3}$ are presented in Figs.14-19. The solid line is for $E_{2}$ and the pointed for $E_{3}$. Evidently, the negative values of $E_{3}$ are much more rare and have much smaller amplitudes when compared to $E_{2}$. Also, the negative values of $E_{3}$ are confined to very narrow tropical zone and all of them are clustered near boarder line between negative and positive values.

If we compare the results for $\mathrm{E}_{3}$ with the respective results obtained for realizability conditions by Kasahara (1982) and Knox (1997), we can note a great similarity. Indeed, the use of ellipticity criterion $\mathrm{E}_{3}$ allows to recover ellipticity in the major part of the negative area of the measure $E_{2}$ and to strongly decrease the remaining negative values bringing them to the boarder line. The average qualitative distribution of measure $E_{3}$ exhibits the same principal characteristics as the realizability measures, namely, the negative area is confined to tropic-subtropic zone and it increases toward higher pressure levels. The main difference is that the effect of the compensation of negative ellipticity achieved in Kasahara (1982) and Knox (1997) by the inclusion in the realizability conditions of additional terms from the divergence equation, is obtained in our study by substituting the ellipticity criterion for more simple balance relation by another ellipticity criterion corresponding to more complex and justifiable NMI/BDM method. In this way, we substantiate the Kasahara's statement that ellipticity conditions can be violated in the actual atmospheric fields essentially due to approximations made under deriving the balance relations.

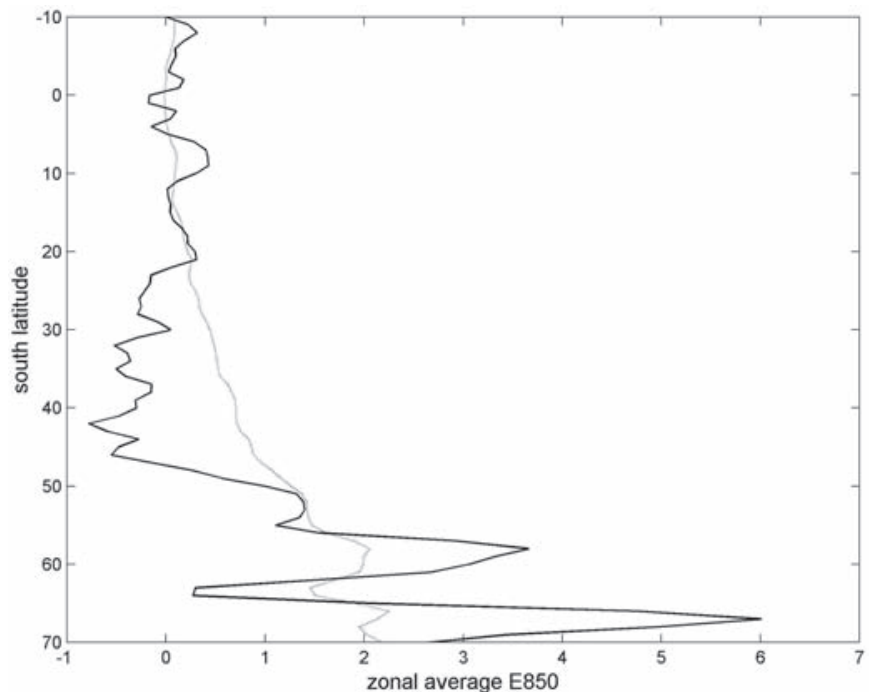

Figure 14 - The longitudinal averages of the measures $E_{2}$ and $E_{3}$ for the East part of the Southern Hemisphere at $850 \mathrm{hPa}$ pressure level as functions of southern latitude. The solid line is for $\mathrm{E}_{2}$ and the pointed for $\mathrm{E}_{3}$. 


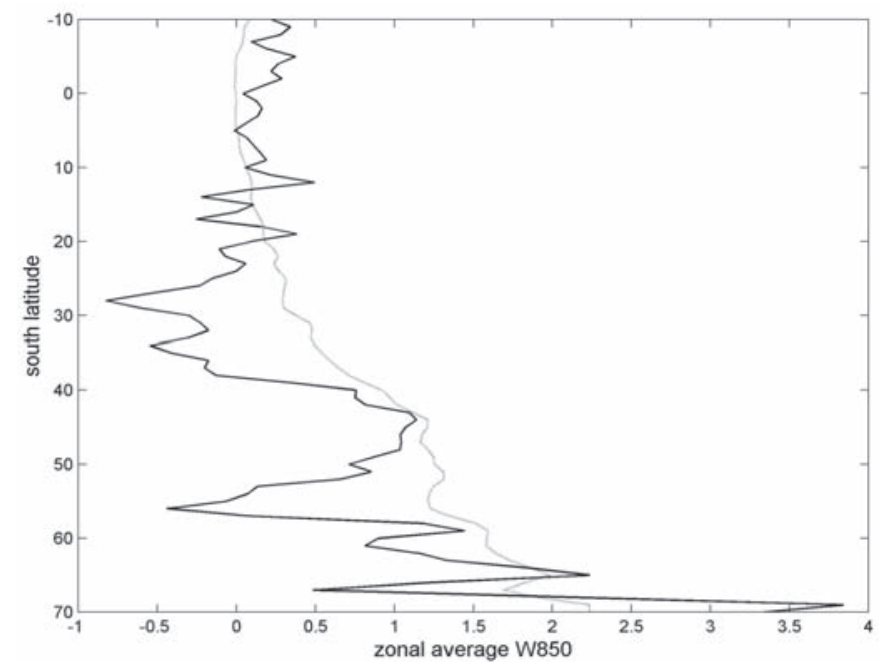

Figure 15 - Same as in Figure 14, except for the West part of the Southern Hemisphere.

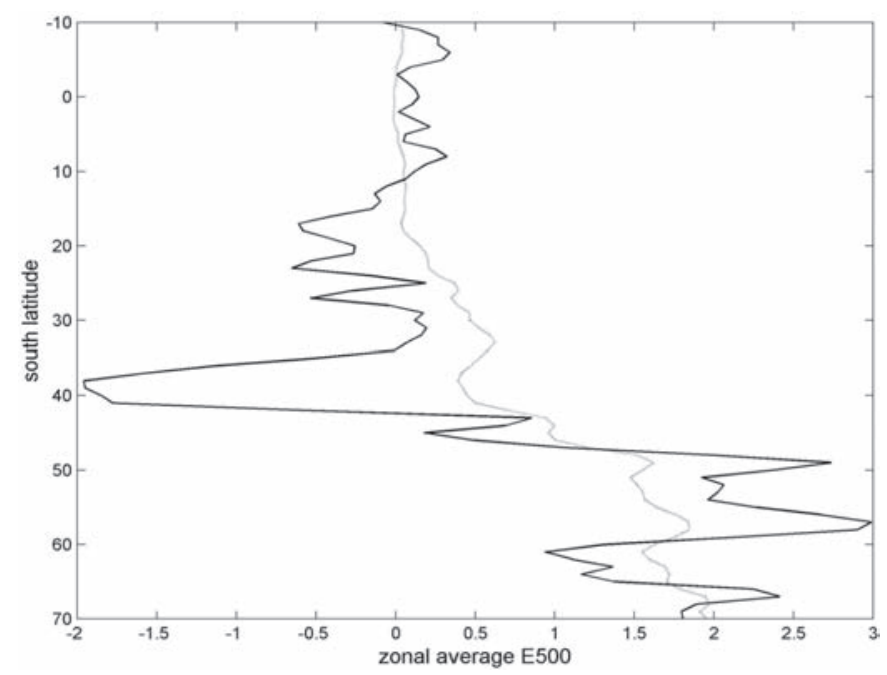

Figure 16 - Same as in Figure 14, except for the $500 \mathrm{hPa}$ pressure level.

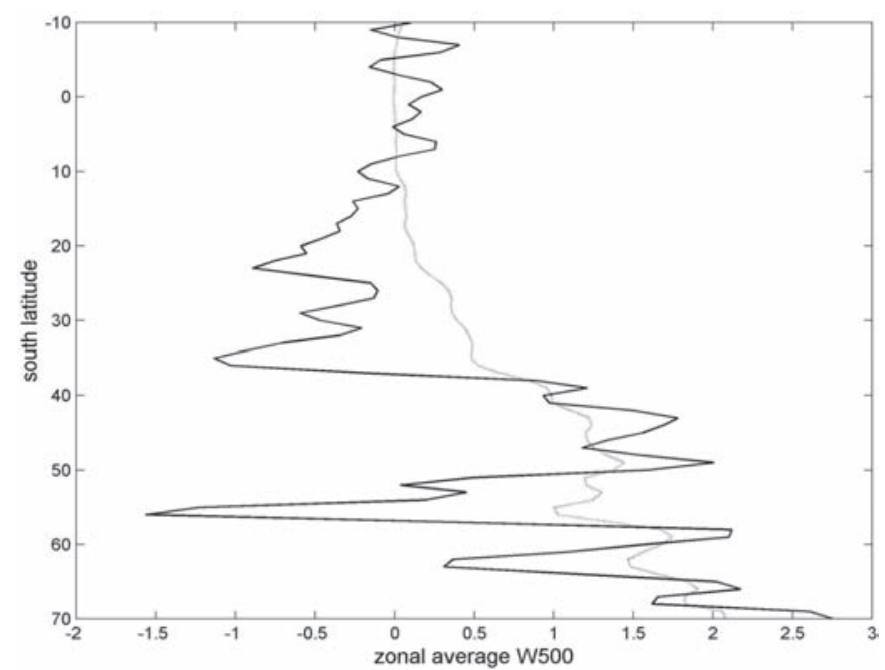

Figure 17 - Same as in Figure 15, except for the $500 \mathrm{hPa}$ pressure level.

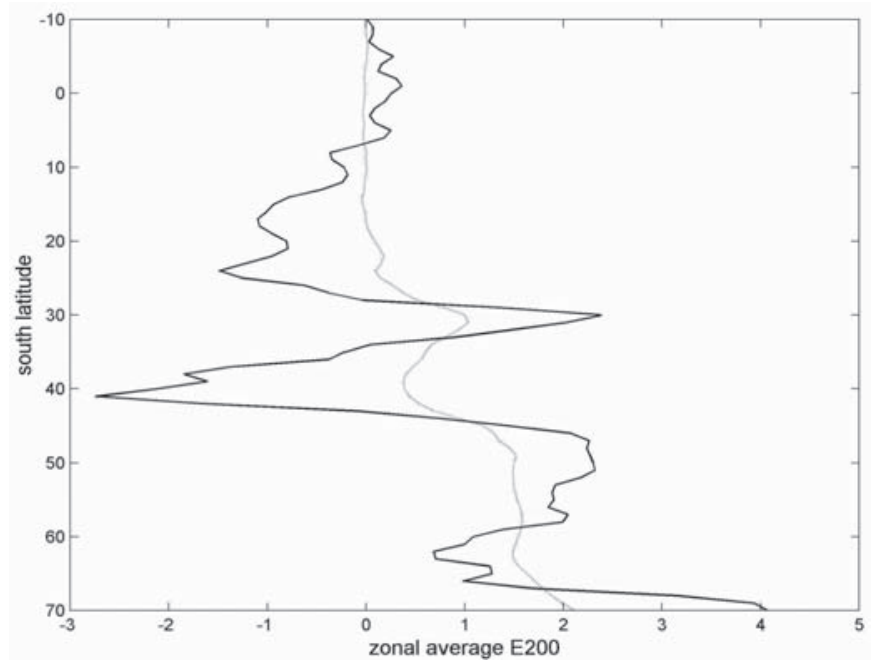

Figure 18 - Same as in Figure 14, except for the $200 \mathrm{hPa}$ pressure level.

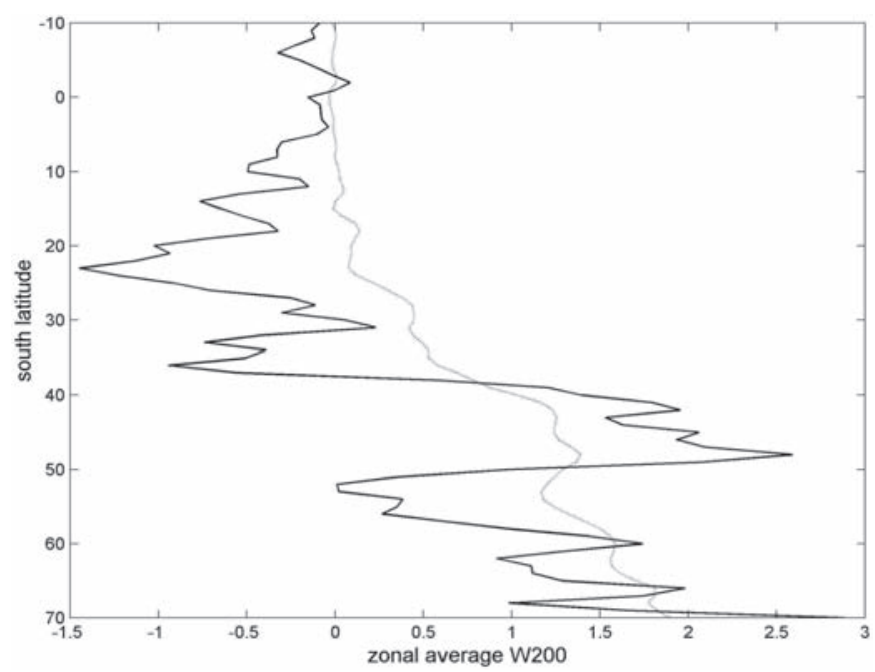

Figure 19 - Same as in Figure 15, except for the $200 \mathrm{hPa}$ pressure level.

\section{CONCLUSIONS}

The nonlinear balance equation introduced by Charney, as well as its spherical generalization introduced by Houghton, and the NMI/BDM initialization equations were considered in this work. The ellipticity conditions associated with these balance relations were presented and the respective nonelliptic regions were found using the gridded data of Southern Hemisphere. These are practically all known until now ellipticity criterions of balance relations, because the well-known Tribbia's condition for spectrally reduced shallow water system virtually coincides with the Charney criterion of nonellipticity. The obtained results showed the existence of nonelliptic regions even for more complex balance systems of the NMI/BDM method. However, these regions have essentially smaller areas and intensity as 
compared with those for nonlinear balance equation. This result confirms the Kasahara's conclusion that the occurrence of nonelliptic regions is of physical nature and related to making simplifications in the derivation of the balance relations.

\section{ACKNOWLEDGEMENTS}

All the geographical charts were plotted with the use of free software GrADS (Grid Analysis and Display System). This research was supported by Brazilian science foundations CNPq and FAPERGS.

\section{REFERENCES}

Baer, F.; Tribbia, J.J. On complete filtering of gravity modes through nonlinear initialization. Mon. Wea. Rev., v.105, p.1536-1539, 1977.

Bengtsson, L. Four-dimensional assimilation of meteorological observations. WMO/ICSU Joint Organizing Committee, GARP Publ. Series, No.15, 1975, 76 p.

Bijlsma, S.J.; Hafkenscheid, L.M. Initialization of a limited area model: a comparison between the nonlinear normal mode and bounded derivative methods. Mon. Wea. Rev., v.114, p.1445-1455, 1986.

Bourchtein, A. Ellipticity of normal mode initialization equations. Appl. Math. Comput., v.133, p.193-211, 2002.

Bourchtein, A. Ellipticity conditions of the shallow water balance equations for atmospheric data. J. Atmos. Sci., v.63, p.1559-1566, 2006.

Bourke, W.; McGregor, T. A nonlinear vertical mode initialization scheme for a limited area prediction model. Mon. Wea. Rev., v.111, p.2285-2297, 1983.

Browning, G.L.; Kasahara, A.; Kreiss, H.-O. Initialization of the primitive equations by the bounded derivative method. J. Atmos. Sci., v.37, p.1424-1436, 1980.

Charney, J. The use of the primitive equations of motion in numerical prediction. Tellus, v.7, p.22-26, 1955.

Daley, R. Variational nonlinear normal mode initialization. Tellus, v.30, p.201-218, 1978.

Daley, R. Normal mode initialization. Rev. of Geoph. and Space Phys., v.19, p.450-468, 1981.
Daley, R. Atmospheric data analysis. Cambridge University Press, 1991, 457 p.

Errico, R.M. Convergence properties of Machenhauer's initialization scheme. Mon. Wea. Rev., v.111, p.2214-2223, 1983.

Fillion, L.; Roch, M. Variational implicit normal mode initialization for a multilevel model. Mon. Wea. Rev., v.120, p.1051-1076, 1992.

Houghton, D.D. Derivation of the elliptic condition for the balance equation in spherical coordinates. Generalized nonlinear balance criteria and inertial stability. J.Atmos. Sci., v.25, p.927-928, 1968.

Kasahara, A. Nonlinear normal mode initialization and the bounded derivative method. Rev. of Geoph. and Space Phys., v.20, p.385-397, 1982.

Kasahara, A. Significance of non-elliptic regions in balanced flows of the tropical atmosphere. Mon. Wea. Rev., v.110, p.1956-1967, 1982.

Knox, J.A. Generalized nonlinear balance criteria and inertial stability. J.Atmos. Sci., v.54, p.967-985, 1997.

Lynch, P.; Huang, X.-Y. Initialization of the HIRLAM model using a digital filter. Mon. Wea. Rev., v.120, p.1019-1034, 1992.

Machenhauer, B. On the dynamics of gravity oscillations in a shallow water model, with applications to normal mode initialization. Contrib. Atmos. Phys., v.50, p.253-271, 1977.

McGregor, T.; Bourke, W. A comparison of vertical mode and normal mode initialization. Mon. Wea. Rev., v.116, p.13201334,1988

Paegle, J.; Paegle, J.N.; Dodd, G.C. On the occurence of atmospheric states that are non-elliptic for the balance equations. Mon. Wea. Rev., v.111, p.1709-1723, 1983.

Randel, W.J. The evaluation of winds from geopotential height data in stratosphere. J. Atmos. Sci., v.44, p.3097-3120, 1987.

Rasch, P.J. Developments in normal mode initialization. Part II. A new method and its comparison with currently used schemes. Mon. Wea. Rev., v.113, p.1753-1770, 1985. 
Temperton, C. Implicit normal mode initialization. Mon. Wea. Rev., v.116, p.1013-1031, 1988.

Temperton, C.; Roch, M. Implicit normal mode initialization for an operational regional model. Mon. Wea. Rev., v.119, p.667-677, 1991.

Tribbia, J.J. Nonlinear normal mode balancing and the ellipticity condition. Mon. Wea. Rev., v.109, p.1751-1761, 1981. 